\title{
Particle precipitations during NEIAL events: simultaneous ground based observations at Svalbard
}

\author{
J. Lunde ${ }^{1, *}$, B. Gustavsson ${ }^{1}$, U. P. Løvhaug ${ }^{1}$, D. A. Lorentzen ${ }^{2}$, and Y. Ogawa ${ }^{3}$ \\ ${ }^{1}$ Department of Physics, University of Troms $\varnothing$, Troms $\varnothing$, Norway \\ ${ }^{2}$ Geophysics Department, University Centre on Svalbard, Longyearbyen, Svalbard \\ ${ }^{3}$ National Institute of Polar Research, Tokyo, Japan \\ *now at: Solar Terrestrial Environment Laboratory, Nagoya University, Japan
}

Received: 9 August 2006 - Revised: 16 May 2007 - Accepted: 28 May 2007 - Published: 29 June 2007

\begin{abstract}
In this paper we present Naturally Enhanced Ion Acoustic Lines (NEIALs) observed with the EISCAT Svalbard Radar (ESR). For the first time, long sequences of NEIALs are recorded, with more than 50 events within an hour, ranging from 6.4 to $140 \mathrm{~s}$ in duration. The events took place from $\sim 08: 45$ to 10:00 UT, 22 January 2004. We combine ESR data with observations of optical aurora by a meridian scanning photometer at wavelengths 557.7, 630.0, 427.8 , and $844.6 \mathrm{~nm}$, as well as records from a magnetometer and an imaging riometer. The large numbers of observed NEIALs together with these additional observations, enable us to characterise the particle precipitation during the NEIAL events. We find that the intensities in all optical lines studied must be above a certain level for the NEIALs to appear. We also find that the soft particle precipitation is associated with the down-shifted shoulder in the incoherent scatter spectrum, and that harder precipitation may play a role in the enhancement of the up-shifted shoulder. The minimum energy flux during NEIAL events found in this study was $\sim 3.5 \mathrm{~mW} / \mathrm{m}^{2}$ and minimum characteristic energy around $50 \mathrm{eV}$.
\end{abstract}

Keywords. Ionosphere (Particle precipitation; Plasma waves and instabilities; Polar ionosphere)

\section{Introduction}

Naturally enhanced ion acoustic lines are intermittently seen in spectra from incoherent scatter radars (ISR) at high latitudes. The characteristic incoherent scatter spectrum of NEIAL events is easily distinguished from the thermal spectra by the enhancement of one, or both, ion acoustic shoulders. The enhancements are typically $1-2$ orders of magnitude in power compared to normal ion line values (Rietveld et al., 1991; Collis et al., 1991). The NEIALs have

Correspondence to: J. Lunde

(june.lunde@phys.uit.no) been observed in the nightside auroral oval as well as in the cusp/cleft region. The first observation of NEIALs was reported by Foster et al. (1988) using the Millstone Hill radar $(440 \mathrm{MHz})$ pointed to the north. Later on, similar observations were made in Troms $\varnothing$, which is located within the auroral zone, using the EISCAT radars $(224 \mathrm{MHz}$ and $931 \mathrm{MHz})$ by Collis et al. (1991) and Rietveld et al. (1991). Further north, Buchert et al. (1999) observed NEIALs for the first time in the dayside cusp/cleft region using the EISCAT Svalbard Radar (500 MHz).

Since the first observations, many papers have been published in order to explain the physical mechanisms behind the NEIAL phenomena (see Sedgemore-Schulthess and St.Maurice, 2001, and references therein). Although the understanding of the NEIAL phenomenon is not clear, a common theme among the explanations is instability processes where particle precipitation is directely or indirectely involved. It is therefore of interest to study the characteristics of the precipitation during such events.

NEIALs are typically observed in the upper F-region, between $\sim 300$ and $700 \mathrm{~km}$. They are rarely observed below $200 \mathrm{~km}$ or above $1000 \mathrm{~km}$, but they do occur intermittently as low as $138 \mathrm{~km}$ (Rietveld et al., 1991) and as high as $1600 \mathrm{~km}$ (Ogawa et al., 2006). NEIALs are a fine scale phenomena, Rietveld et al. (1996) estimated the transverse size to be a few km, and Grydeland et al. (2003) observed NEIALs with transverse sizes down a few hundred metres or less. The small scale size, together with the enhanced signal, requires that the scattering cross section inside the filament must be 4-5 orders of magnitude above thermal levels (Grydeland et al., 2003, 2004).

NEIALs have been observationally associated with a wide range of geophysical phenomena which can be summaries as follows:

- Severe Geomagnetic Disturbances (e.g. Rietveld et al., 1991)

Published by Copernicus Publications on behalf of the European Geosciences Union. 
- Soft Precipitation (e.g. Collis et al., 1991; Forme et al., 1995)

- High Electron Temperature (e.g. Foster et al., 1988; Wahlund et al., 1993)

- Electric Heating in the F-region (e.g. Rietveld et al., 1991)

- Density enhancement in E-region (e.g. Rietveld et al., 1991; Forme et al., 1995 )

- Intense Ion Out-Flow (e.g. Wahlund et al., 1992a; Forme and Fontaine 1999)

- Red Aurora (e.g. Collis et al., 1991; SedgemoreSchulthess et al., 1999)

- Enhanced Plasma Lines (Strømme et al., 2005)

- Active Aurora (e.g. Sedgemore-Schulthess et al., 1999; Blixt et al., 2005)

As illustrated by this list, particle precipitation, directly or indirectly, seems to be frequently involved in the formation of NEIAL.

Rietveld et al. (1991), using the EISCAT mainland systems, observed enhanced echoes at times of major geomagnetic disturbances (typically $500 \mathrm{nT}$ deflection of the horizontal component at Tromsø). This was during auroral particle precipitation and E-region density enhancement at $120 \mathrm{~km}$, corresponding to precipitation of a few $\mathrm{keV}$. The enhanced echoes were seen both along and slightly off $\left(14.5^{\circ}\right)$ the magnetic field direction. The ISR data showed high electron temperatures at $450 \mathrm{~km}$ altitude varying between $\sim 4000-8000 \mathrm{~K}$, and a high ratio between the electron- and ion- temperatures $\left(T_{e} / T_{i} \geq 2\right)$ for all events. In addition, increased ion outflow above $350 \mathrm{~km}$ altitude where seen in most cases, and an all-sky camera showed red aurora in the F-region and green aurora in the E-region. Collis et al. (1991) reported observations from the EISCAT UHF where all cases of enhanced spectra, for which optical data existed, were accompanied by active and intense red auroral forms in the Fregion. The red line intensity was unusually high with a maximum of $270 \mathrm{kR}$. In contrast, measurements the three previous winters with the same instrument at the same location, showed a maximum of $15 \mathrm{kR}$.

Forme et al. (1995) and Forme and Fontaine (1999), also using the the EISCAT mainland systems, found that strongly asymmetric enhanced ion lines were often associated with elevated electron temperatures, ion outflow with both large ion flux $\left(\sim 10^{14} \mathrm{~m}^{-2} \mathrm{~s}^{-1}\right)$ and vertical velocities $(\sim 1300 \mathrm{~m} / \mathrm{s})$, auroral arcs and precipitating particles of $100 \mathrm{eV}$ to $10 \mathrm{keV}$. Interestingly, Forme et al. (1995) found that observations with both ion lines enhanced, corresponded mostly to slightly enhanced electron temperatures, no ion outflow, and an apparent lack of precipitating particles less than $1 \mathrm{keV}$. The association of NEIALs with ion outflow was confirmed by
Wahlund et al. (1992a), also using the EISCAT VHF and UHF radars. They observed strong field-aligned bulk ion outflows from the topside ionosphere. The ions were mainly $\mathrm{O}^{+}$obtaining velocities of $1500 \mathrm{~m} / \mathrm{s}$ above $900 \mathrm{~km}$ altitude. Two different types of ion-outflow were identified: Type I is related to periods of strong perpendicular electric fields, enhanced and anisotropic ion temperatures in the upper ionosphere down to the E-region and very low electron densities below $300 \mathrm{~km}$, the last indicating small amounts of auroral precipitation. Type II is related to auroral arcs and enhanced electron temperatures $(>6000 \mathrm{~K})$, as well as isotropic ion temperatures and weak to moderately strong perpendicular electric field. During short intervals of auroral precipitation and Type II outflows, they occasionally observed NEIALs.

Sedgemore et al. (1999) observed poleward moving auroral transients in the dayside cusp/cleft region by a meridian scanning phototometer around the time when the enhanced radar spectra appeared. The topside electron-to-ion temperature ratio was about 3 . They also observed that coronal forms were present in the optical narrow-angle images only when enhanced spectra were seen. Blixt et al. (2005) reported very dynamic rayed auroras in the dayside cusp/cleft region observed with high-resolution narrow field-of-view auroral imagers simultaneously with occurrences of enhanced ionacoustic echoes. Additionally, red auroral emissions were seen in the photometer data during all events. Strømme et al. (2005) related simultaneous enhancements in the ion and plasma lines due to a low energy electron beam $(8-80 \mathrm{eV})$.

The instability processes proposed in the literature to explain the NEIAL phenomenon are: i) Current Driven Instability (Foster et al., 1988; Collis et al., 1991; Rietveld et al., 1991), ii) Ion-Ion Two-Stream Instability (Wahlund et al., 1992b) and iii) Parametric Decay of Langmuir Waves (Forme, 1993 and 1999). They can be summarized as follows:

i) Current driven instability, also known as ion-electron two-stream instability, is ion acoustic instabilities driven by thermal electron drifts. This requires large fieldaligned current (FAC) densities, on order of $1 \mathrm{~mA} / \mathrm{m}^{2}$, which could be produced by parallel electric fields caused by precipitating particles or horizontal conductivity. Such currents have recently been measured with the Ørsted Satellite (Neubert and Christiansen, 2003). It is the thermal electrons that carry the current; hence, it might be difficult to explain the occasional observations of simultaneous enhancements in both ion lines.

ii) Ion-ion two-stream instability (ion-ion drift instability or counter streaming ion populations), is driven by large relative drifts between two or more ion species, for exemple $\mathrm{O}^{+}$and a beam of $\mathrm{H}^{+}$. As long as the drift velocity is of the order of the species thermal velocity, the ion acoustic fluctuation level can be enhanced well above the thermal level, leading to an enhancement in one or both ion lines. The high relative drifts require 
a sufficient acceleration of $\mathrm{H}^{+}$, which might be possible at high altitudes. Accordingly, with this mechanism, NEIALs are unlikely to occur at low altitudes, but could occur in the upper part of and above the F-region. However, if there are processes that accelerate either $\mathrm{O}^{+}$or $\mathrm{NO}^{+}$, an instability process could occur at lower ionospheric altitudes.

iii) Parametric decay of Langmuir waves is the destabilization of an ion acoustic wave through quasi-linear wave coupling with high frequency Langmuir (plasma) waves, which can lead to enhanced ion acoustic fluctuations. A downward electron beam of 10 to $500 \mathrm{eV}$ resulting in a bump in tail in the electron distribution, can lead to excitation of Langmuir waves which drive the wave-wave interaction. It has been shown that for reasonable beam parameters, the parametric decay of beam-generated Langmuir waves can enhance the right, the left or both ion lines simultaneously. This theory does not require large parallel current densities or large differential ion drifts, but requires low energy precipitating electrons as the triggering mechanism. Thus this theory favours type II outflow, which imply enhanced electron temperature together with auroral precipitation, with typical ratios between the electron- and ion temperature of 3 or higher. Pursuant to this theory, NEIALs are not likely to occur during more energetic precipitation $(>500 \mathrm{eV})$ without a soft component.

The works by Strømme et al. (2005) and Ogawa et al. (2006) support the parametric decay of Langmuir waves, while modelling performed by Nöel et al. (2000) support the theory of current driven instability. In the latter high energy precipitation (mean electron energy $1.62 \mathrm{keV}$ ) was used as input, and the current continuity equation solved, allowing for timedependency. The model was computed for nighttime conditions.

The coarse division of energetic electrons into "hard" and "soft" is of course arbitary. Here we take the transition to be at $500 \mathrm{eV}$. Various values of this transition are found in the literature, often depending on the problem under discussion. For example, $1 \mathrm{keV}$ is frequently used when dealing with aurora in order to distinguish between the particles causing dayside and those causing nightside auroras. In papers on NEIALs, soft electrons are often defined as having energies below $100 \mathrm{eV}$. We have chosen a limit of $500 \mathrm{eV}$ because the precipitation is poleward of the open/closed boundary (OCB). In the dayside, the auroral oval (soft precipitation) will be located polewards of the OCB. On the equatorward side, high energy particles - typically from the central plasma sheet - dominates. Since our observations are performed during typical cusp hours, 12:00 MLT $+/-1.5 \mathrm{~h}$, an input of low energy electron precipitation, presumably from the cusp region, is expected (Heikkila and Winningham, 1971; Frank, 1971; Newell et al., 2004).
Primary auroral electron fluxes have a wide range of energy distributions. The spectral energy distribution of primary electrons in the range of $100 \mathrm{eV}$ to some tens of $\mathrm{keV}$ is often found to be almost Maxwellian (Rees and Luckey, 1974). However, satellite data collected over the years show that the spectra can often be more sharply peaked than a Maxwellian distribution, closer to a Gaussian energy distribution (Strickland et al., 1989; Hecht et al. 1999). The Maxwellian form is mostly related to diffuse aurora, while the Gaussian form is associated with discrete aurora (Lyons, 1992). Large electron fluxes below $100 \mathrm{eV}$ consist almost entirely of secondary electrons (Rees and Maeda, 1973), and the energy distribution of secondary electrons is better approximated with power law (Frank and Ackerson, 1971; Ogilvie, 1968). To roughly characterise the energy of the precipitating electrons by a single number, the average over the distributions is always an option. Both Gaussian and Maxwellian distributions can, however, be described by a mathematical parameter, a so-called characteristic energy, $E_{0}$. For a Gaussian distribution the characteristic energy is equal to the average energy, $E_{0}=<E>$, (Strickland et al., 1993), while for a Maxwellian distribution, it is equal to one half of the average energy, $E_{0}=<E>/ 2$, (Vallance-Jones et al., 1987).

In the isotropic case the Maxwellian distribution can be written as:

$\Phi_{M}(E)=\left(\frac{Q_{M}}{2 \pi \cdot E_{0}^{3}}\right) \cdot E \exp \left[-E / E_{0}\right]$ [electrons $\left./ \mathrm{cm}^{2} \mathrm{seV} \mathrm{sr}\right]$

$\Phi_{M}(E)$ denoting the differential electron number flux at the electron energy $E, Q_{M}$ the energy flux, and $E_{0}$ the characteristic energy which also is the energy for the peak of the distribution.

Correspondingly the Gauss distribution is expressed as

$\Phi_{G}(E)=\left(\frac{Q_{G}}{\pi^{3 / 2} \cdot W E_{0}}\right) \cdot \exp \left[-\left(\frac{E-E_{0}}{W}\right)^{2}\right]$ [electrons $\left./ \mathrm{cm}^{2} \mathrm{seV} \mathrm{sr}\right]$

$W$ being a scaling parameter.

For a more complete model of the distribution, a highenergy-tail (HET) and a low energy-tail (LET) should be added to the Gaussian distribution (Strickland et al., 1993), and a LET to the Maxwellian distribution (Meier et al., 1989). When tails are included the relation between $\langle E\rangle$ and $E_{0}$ is modified. We get $<E>=1.4 E_{0}$ for the Maxwellian distribution and $<E>=0.5 E_{0}$ for the Gaussian distribution (Meier et al., 1989).

When discussing the role of the particle precipitation in physical mechanisms behind the NEIALs, most papers, observational as well as theoretical ones, focus on the soft particle precipitation. The authors of this paper believe that including more energetic precipitation may improve the understanding of NEIAL.

We have obtained with the ESR what we believe is a unique data set, where NEIALs occur very frequently over a period of an hour. We combine this with observations from a 
multi channel meridian scanning photometer, a magnetometer and an imaging riometer. The photometer observations are used to derive energy flux and characteristic energy of the soft part of the particle precipitation, while riometer and magnetometer serve to identify the precence of hard electron precipitation.

\section{Instrumentation}

\subsection{Radar}

The Eiscat Svalbard Radar (ESR) is located in Longyearbyen $\left(78.15^{\circ} \mathrm{N}, 16.03^{\circ} \mathrm{E}\right.$ geographically and $75.27^{\circ} \mathrm{N}, 111.65^{\circ} \mathrm{E}$ CGM). The ESR is a $500 \mathrm{MHz}$ monostatic incoherent scatter radar, transmitting with a peak power of $\sim 1 \mathrm{MW}$ and $25 \%$ duty cycle, and receiving with the same antenna. The radar system consists of two parabolic antennas, $32 \mathrm{~m}$ and $42 \mathrm{~m}$ in diameter. In this paper we only use data from the $42 \mathrm{~m}$ antenna. This is fixed in the magnetic field-aligned position at $\sim 300 \mathrm{~km}$, equal to $182.1^{\circ}$ in azimuth and $81.6^{\circ}$ in elevation. The radar was run with a 16 bit alternating code experiment Tau0, version 5.1, with $16 \mu$ s sampling interval, which imply a range ambiguity function of width $2.4 \mathrm{~km}$. The range coverage was between $78 \mathrm{~km}$ and $1250 \mathrm{~km}$. Integration time was $6.4 \mathrm{~s}$. More detailed description of the ESR facility and techniques can be found in Wannberg et al. (1997).

\subsection{Optical}

The Meridian Scanning Photometer (MSP) is situated at the Auroral Station in Adventdalen, $\sim 7 \mathrm{~km}$ from the radar site. This MSP instrument measures auroral emissions at five wavelengths. In this paper four lines are used: i) the green line at $557.7 \mathrm{~nm}$ of atomic oxygen (OI), ii) the red line at $630.0 \mathrm{~nm}$ of atomic oxygen (OI), iii) the blue line at $427.8 \mathrm{~nm}$ of the first negative band of molecular nitrogen ions $\left(\mathrm{N}_{2}^{+} 1 \mathrm{NG}\right)$, and iv) a near infrared (NIR) line at $844.6 \mathrm{~nm}$ of atomic oxygen (OI).

A full meridian scan with the background subtracted is obtained for each of the channels every $16 \mathrm{~s}$. The scan is close to the magnetic meridian with an angular resolution of $1^{\circ}$. It starts at $10^{\circ}$ elevation in the north and ends at the same elevation in the south, $98^{\circ}$ corresponds to local magnetic zenith. This corresponds to a magnetic latitude ranging from $80^{\circ}$ to $70^{\circ}$ at $120 \mathrm{~km}$ and $84^{\circ}$ to $65^{\circ}$ at $300 \mathrm{~km}$. Further description of the MSP instrument can be found in Romick (1976).

In principle, the optical data should be corrected for airglow and proton-excited emissions (Eather and Mende, 1972). However, the intensities recorded always were well above this background level, and for high-latitude daytime aurora, the proton energy is expected to be low. We have therefore ignored both corrections. The calibration is roughly correct, at least the $427.8 \mathrm{~nm}$ and $630.0 \mathrm{~nm}$ should be reliable, even though that the photometer has not been absolute calibrated for some time. An all-sky imager being op- erated at the same time and place as the MSP instrument, indeed support strong emission intensities, as the large fieldof-view image were almost saturated. It may also be noted that the characteristic energy at $\sim 09: 40 \mathrm{UT}$, is corroborated by data from the DMSP satelellite (not shown) passing over Longyearbyen at that time, thus confirming the photometer calibration is not seriously wrong. The DMSP data might also otherwise have contributed to this paper, we have, however, limited our scope to the ground based instruments.

\subsection{Magnetometer}

The magnetometer is also situated at the Auroral Station. It is a standard 3-axis-fluxgate-magnetometer measuring in both magnitude and direction of the local magnetic field with a time resolution of $10 \mathrm{~s}$.

\subsection{Riometer}

We have used data from an imaging riometer located in $\mathrm{Ny}-$ Ålesund $\left(78.92^{\circ} \mathrm{N}, 11.95^{\circ} \mathrm{E}\right.$ geographically and $76.27^{\circ} \mathrm{N}$, $110.72^{\circ} \mathrm{E}$ CGM), $117 \mathrm{~km}$ north-west of the radar site. The riometer operates at a frequency of $30 \mathrm{MHz}$ within a protected radio-astronomy band to measure ionospheric absorption of cosmic radio noise in the polar cap and auroral region. The sensitivity of the instrument is $0.1 \mathrm{~dB}$. The system consists of 64 single dipole elements, configured into $(8 \times 8)$ narrow beams by a Butler matrix phasing system. This corresponds to a field of view equal to $200 \mathrm{~km} \times 200 \mathrm{~km}$ on either side of zenith at a height of $90 \mathrm{~km}$. There are 8 beams in the east-west direction (E1-E8 starting from east) and 8 beams in the north-south direction (N1-N8 starting from north), and Longyearbyen is within the N5E3 beam. The spatial resolution is $20 \mathrm{~km}$ for the centre and $40 \mathrm{~km}$ at the edge and the sample interval is $4 \mathrm{~s}$. Detailed performances of the IRIS system is reported by Yamagishi et al. (1992) and Sato et al. (1992). There is also an imaging riometer installed in Longyerabyen, but data were not available for this particular day.

\section{Observations}

\subsection{Geophysical conditions}

The observations took place on 22 January 2004, between 08:00-10:00 UT, the last hour being the more interesting due to the large numbers of NEIALs. Magnetic noon for Longyearbyen is at $\sim 08: 51$ UT (IGRF-2004), the observations therefore fall within the cusp/cleft region. The polar cusp is the region of open-field-lines just poleward of the boundary between open and closed field lines on the dayside, while the cleft, also known as the Low Latitude Boundary Layer (LLBL), can be found downstream along the flanks of the magnetotail. Satellite measurements show that electrons 
in the energy range $30-100 \mathrm{eV}$ and $70-200 \mathrm{eV}$ dominate the cusp and LLBL, respectively (Newell and Meng, 1992).

The 22 January 2004 was geophysically an active day. This was probably related to a halo Coronal Mass Ejection (CME) which occurred 2 days ahead, with a gusty outflow (Fazakerley et al., 2005). The local $K$-index for Longyearbyen was around 5 with a maximum of 7 just after midnight. This fits well with the statistical studies of $5000 \mathrm{~h}$ of data, performed by Rietveld et al. (1996), which show that the $K$-index is greater than or equal to 4 during NEIAL events. The $K_{p}$-index showed quite similar values and we conclude that the observations took place during a moderate magnetic storm. This is confirmed by the $D_{s t}$ index. Aditionally, MIRACLE, a two-dimensional instrument network for mesoscale studies of auroral electrodynamics (http: //space.fmi.fi/MIRACLE/index.html), shows the presence of an ionospheric equivalent current and Joule heating this day, not only just after midnight, but also significantly immediately before the NEIAL events. In the time span of interest, the interplanetary magnetic field (IMF) $B_{z}$ component was positive (northward) while the $B_{y}$ component was strongly negative (dawnward) in the ecliptic plane.

\subsection{Radar}

By visual inspections of the raw data dumps from the $42 \mathrm{~m}$ antenna, a total of 68 individual NEIAL events were identified among the 563 integration periods between 08:0010:00 UT. An overwiew of the returned backscatter power versus time and altitude is shown in Fig. 1; there the NEIAL events can be seen as extended vertical lines in the F-region. In several cases these lines of increased backscatter extend into the E-region as well. These phenomena in the E-region should not automatically be taken as signs of NEIALs, more likely they are enhanced electron density du to bursts of hard particles. Compared to previously reported observations, the number of events is remarkably high. In contrast, only 5 events were found in a case study with a similar time span on 24 January 1998 at ESR (Sedgemore-Schulthess et al., 1999). In several cases, NEIALs occurred in consecutive dumps, up to 13 in a row, while 41 occurred alone. The first event observed took place at $\sim 08: 53$ UT, while the final one ended at 09:55 UT. Typically, the NEIALs appear on very short time scales, down to less than a second (Grydeland et al., 2004). However, our time resolution is limited to $6.4 \mathrm{~s}$ (the integration time), and the individual number of events may therefore be much larger. The longest duration of a consecutive NEIAL observation is about $2.2 \mathrm{~min}$. Particularly strong NEIALs were found in 18 data dumps. Of these, 13 had strongly enhanced left (down-shifted) shoulder - in some cases more than $20 \mathrm{~dB}-, 4$ cases showed strong enhancement in the right (up-shifted) shoulder, and in only one case both shoulders were strongly enhanced. Examples of the strongest cases are shown in Fig. 2. It is worth noticing, that the right shoulder is more enhanced at a lower altitude

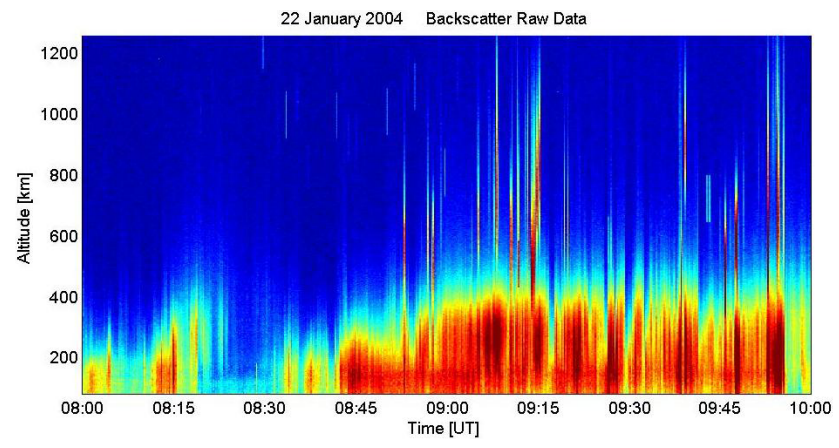

Fig. 1. ESR backscatter versus time and altitude. Red represents strong backscattering. Some of the NEIAL events can be seen as extended vertical lines in F-region, often coinciding with increased backscattering in the E-region. Good examples of this can be seen $\sim 09: 38, \sim 09: 48$ and $\sim 09: 52-09: 52: 55$ UT, and more moderate cases can be seen $\sim 08: 53, \sim 09: 10$ and $\sim 09: 26$.

than the left, and that at higher altitudes, the left shoulder is enhanced more than the right one. This is also the situation when comparing Fig. $2 \mathrm{a}$ with $2 \mathrm{c}$ and $\mathrm{d}$. Note that the spectra present in Figs. 1 and 2 are in the raw form, not corrected for the effect of finite pulse length; hence the spectra are slightly smoothed and broadened.

Altogether, 41 NEIAL events have been categorised as moderately enhanced. Among these, 9 showed roughly equal enhancement in both shoulders, in 28 cases the left shoulder was considerably stronger than the right, and in merely 4 cases the situation was reversed. This is in good agreement with the result by Rietveld et al. (1996), who found that the left shoulder was more commonly enhanced above $450 \mathrm{~km}$ than the right shoulder, and that enhancement in both shoulders can occur above $300 \mathrm{~km}$. Similar to Blixt et al. (2005), we find the NEIALs to be more abundant above $500 \mathrm{~km}$, rather than having a maximum occurrence rate at $500 \mathrm{~km}$ (Rietveld et al., 1996). It should be noted that the latter is a statistical results from the UHF radar. With the VHF radar, a peak is typically seen at about $800 \mathrm{~km}$ (Forme et al., 1995).

Figure 3 displays the result of EISCAT routine analysis. An increased electron density, up to a factor 10 , is observed throughout the F-layer in the NEIAL period, and above $500 \mathrm{~km}$ we see an upward directed ion flow above $400 \mathrm{~m} / \mathrm{s}$, this being in agreement with previous observations by Wahlund et al. (1992), Forme and Fountaine (1999). The electron temperature $\left(T_{e}\right)$ is very high $(>6000 \mathrm{~K})$ and the ratio between the electron and ion temperatures is higher than two. Around the altitude of $600 \mathrm{~km}$ where we have maximum occurrence of NEIALs in our observations, $T_{e}$ increases from roughly $3000 \mathrm{~K}$ to $6000 \mathrm{~K}$. A less pronounced increase is seen in the ion temperature $\left(T_{i}\right), 2400 \mathrm{~K}$ during the NEIAL period, in contrast to $1800 \mathrm{~K}$ before and after. The ratio $T_{e} / T_{i}$ is thus increased from 1.7 outside the NEIAL period to 2.5 within it. At $400 \mathrm{~km}$, which is below most of the NEIALs, $T_{e}$ increases much less, from $3000 \mathrm{~K}$ to $4500 \mathrm{~K}$. 
a)
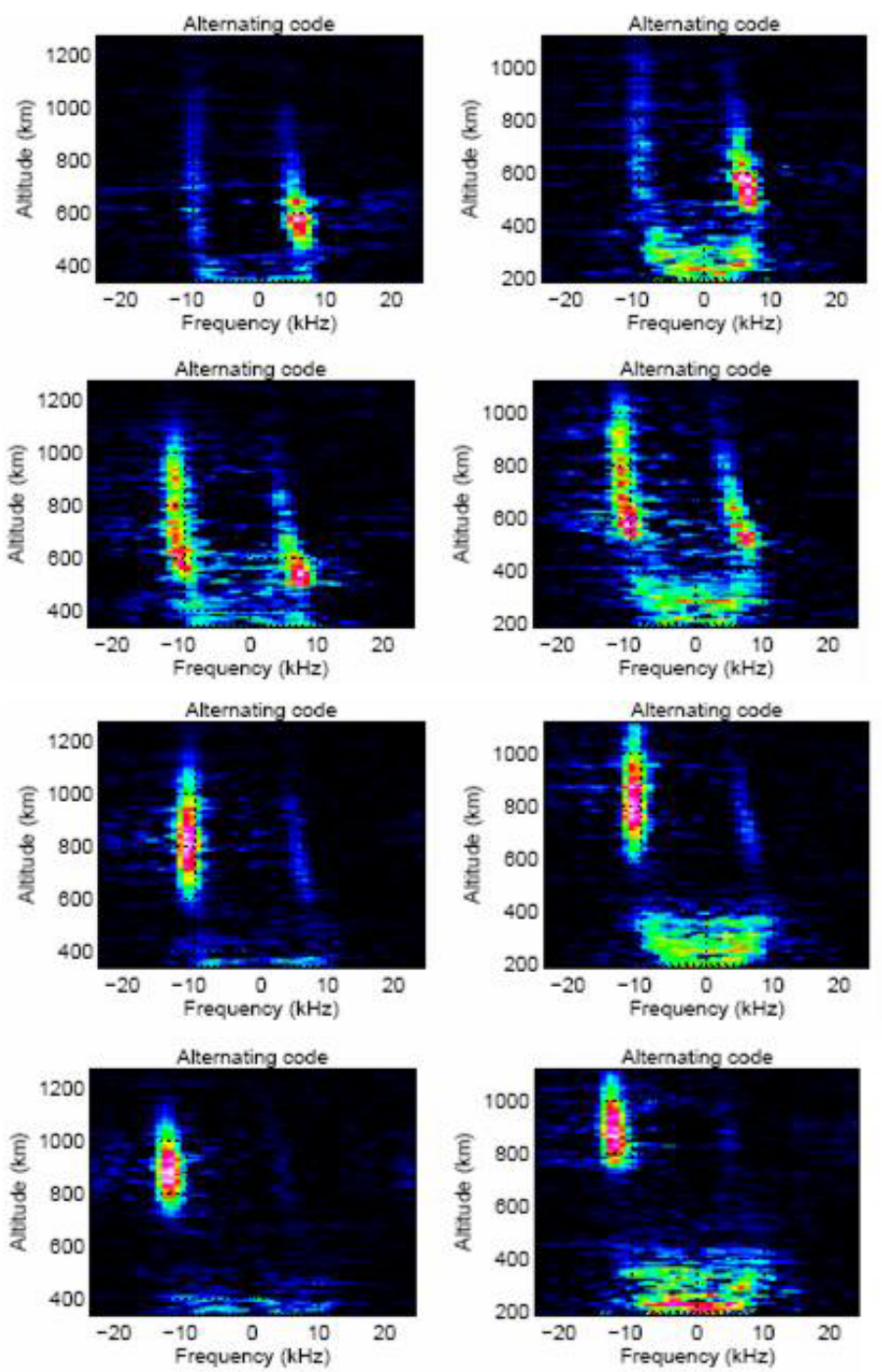

d)
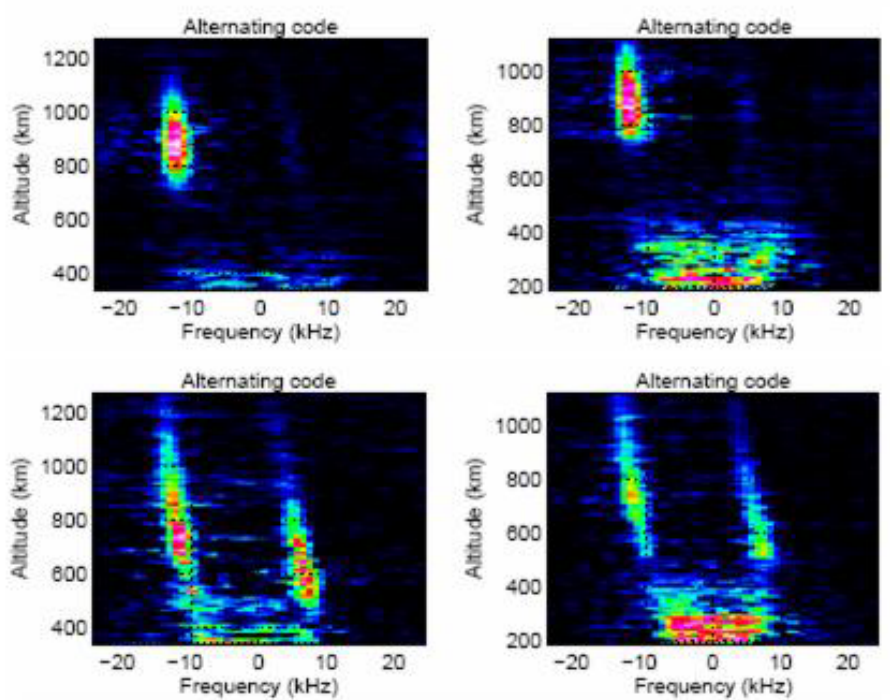

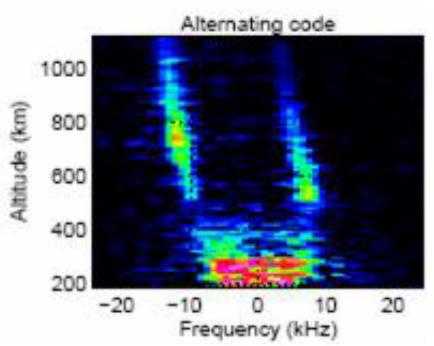

09:10:37 UT

to

09:10:43 UT

09:13:11 UT

to

$09: 13: 17$ UT

09:15:06 UT

to

$09: 15: 12$ UT

$09: 38: 59 \mathrm{UT}$

to

09:39:05 UT

$09: 55: 12$ UT

to

$09: 55: 18 \mathrm{UT}$

Fig. 2. Examples of some of the NEIALs observed between $\sim 08: 52$ and $\sim 09: 55$ UT, with enhancement in one or both shoulders; (a) the right shoulder is much more enhanced than the left, (b) both shoulders are enhanced to about the same level, (c) the left shoulder is much more enhanced than the right, (d) a more height defined enhancement in the left shoulder and (e) the enhancement in both shoulders are left shifted (strong ion outflow). Start and stop of the integration time are given on the right hand side.

Be aware, however, that all physical parameters derived by standard analysis during the NEIAL events must be regarded as corrupted, as the analysis breaks down or gives unrealistic values because of the highly non-thermal spectra. In fact, the failure of the analysis program to fit realistic physical parameters from ISR data is very often a sign of NEIALs being present. This can typically be seen as data gaps in the standard colour plots and/or unrealistically high electron temperatures. 
ESR 42m, January 22, 2004
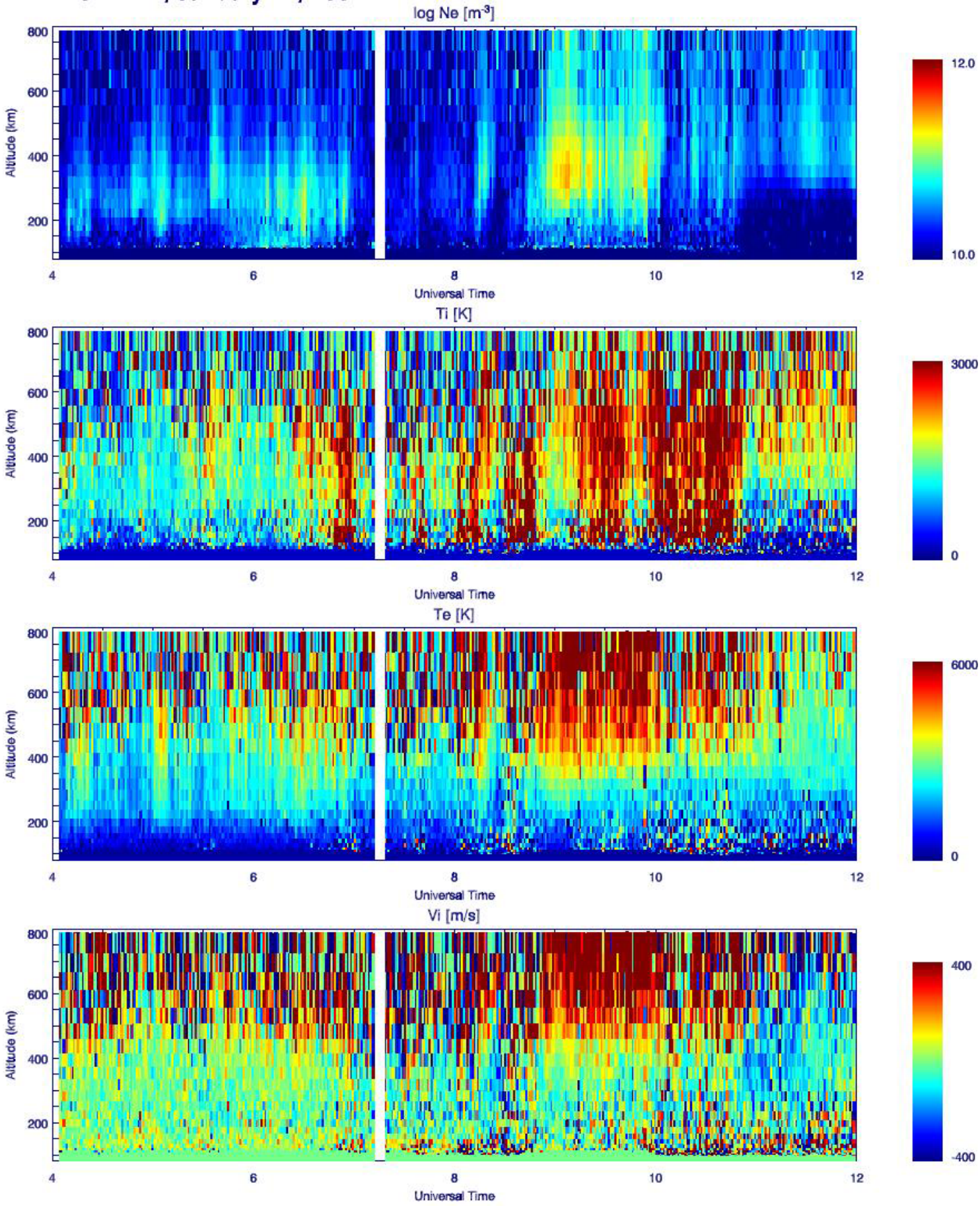

Fig. 3. A standard analysis of the ESR data where the panels show from the top to the bottom: the electron density, the electron temperature, the ion temperature and the ion drift velocity.

\subsection{Optical}

The MSP data displays an increased intensity in all channels after $\sim 08: 25$ UT and especially after $\sim 08: 43$ UT and $\sim 09: 10$ UT. A plot of all the emissions, which overlap the
$42 \mathrm{~m}$ antenna in the field-aligned direction, is presented in Fig. 4. The NEIAL occurrences are marked with red at the prompt emission of $427.8 \mathrm{~nm}$. The optical intensity during periods of NEIALs are found to be between $15 \mathrm{kR}$ and $43 \mathrm{kR}$ for the $630.0 \mathrm{~nm}$, while the corresponding values for 


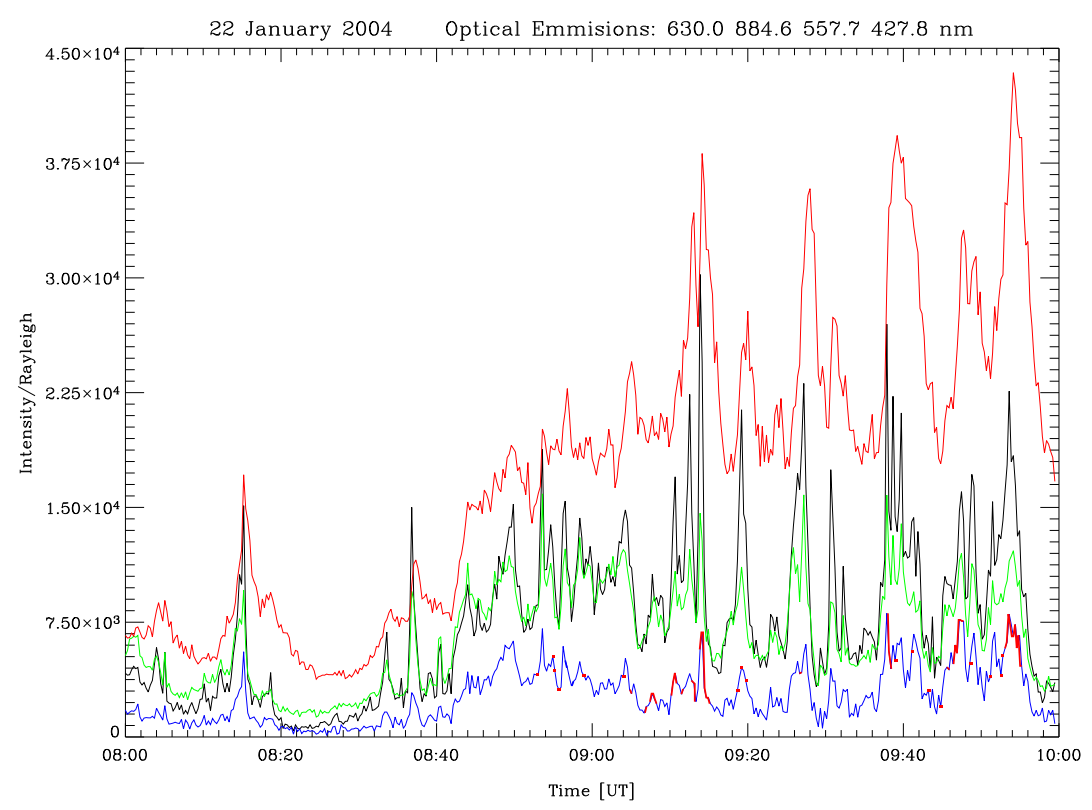

Fig. 4. Optical emissions corresponding to the field-aligned radar beam direction between 08:00-10:00 UT. The curves correspond to intensities of: $630.0 \mathrm{~nm}$ (red), $844.6 \mathrm{~nm}$ (black) $\times 4,557.7 \mathrm{~nm}$ (green) $\times 3$ and $427.8 \mathrm{~nm}$ (blue) $\times 2$. NEIALs are marked with red at the $427.8 \mathrm{~nm}$ curve. Note the delay of $630.0 \mathrm{~nm}$ emission maxima due to the long lifetime.

the other channels are: $\sim 800-4000 \mathrm{R}$ for $427.8 \mathrm{~nm}, \sim 1500$ $5300 \mathrm{R}$ for $557.7 \mathrm{~nm}$ and $\sim 1200-7500 \mathrm{R}$ for $844.6 \mathrm{~nm}$. As for the ratios between the line intensities, we find that NEIAL occur only within an upper and lower limit. For example, the ratio between the red and green line ranges from 3 to 19 , while NEIALs only occur from 5 to 15 . Typically, as long as line intensities are within these limits, enhanced peak intensity (e.g. 08:55, 09:08, 09:10:30, 09:14, 09:38, 09:47:30, 09:54, 09:54:30 and 09:55) in all optical lines corresponds to enhancement in both shoulders in the radar spectra while reduced intensity in all lines except the red line, corresponds to only enhancement in the left shoulder (e.g. 08:55:30, 08:57, 09:10, 09:26:30, 09:39, 09:43, 09:44:30, 09:51, 09:53).

\subsection{Magnetometer}

The horizontal-component $(\mathrm{H})$ of the magnetometer (not shown) has a pronounced negative bay which starts at $\sim 08: 31$ UT and reaches a maximum deflection at $\sim 08: 43$ UT, which is just about $10 \mathrm{~min}$ prior to the first NEIAL record, $\sim 08: 53$ UT. Between 08:00 and 10:00 UT the component varies irregularly over a range of $379 \mathrm{nT}$. The vertical component indicates that the current is approximately overhead. This is verified by data from the IMAGE chain; the magnetic activity is located above and nearby Longyearbyen.

\subsection{Riometer}

Within the time of interest, an absorption event took place at 08:14 UT. Thereafter, the values reached more than $0.5 \mathrm{~dB}$ at 08:20 UT, returning again to a low value at 08:22 UT. After a short quiet period, the absorption started to increase once more just after $\sim 08: 42$ UT with several absorption peaks between 0.5 and $0.8 \mathrm{~dB}$ at: $\sim 08: 53, \sim 09: 10, \sim 09: 18$, $\sim 09: 28, \sim 09: 30, \sim 09: 41, \sim 09: 44$ and $\sim 09: 51$ UT. By comparing the magnetometer data with the riometer data, we find as expected, that a considerable absorption started at the same time as the negative bay in the magnetic $\mathrm{H}$-component reached its very minimum ( 08:43 UT).

\section{Data analysis}

The optical intensities and the ratios between them have been used to derive the total energy flux and the characteristic energy $\left(E_{0}\right)$, the latter being described briefly in the introduction. The intensities of the MSP meridian scans have been smoothed by using a weighted triangular filtering of $+/-1^{\circ}$. We assume a pure Maxwellian distribution form, without the energy tails. The LET has no essential effect on the brightness of the lines with the exception of the red line, because the intensity arises primarily from the F-region, where quenching is small and where the low energy portion of the precipitating electron spectrum deposit its energy (Strickland et al., 1989; Meier et al., 1989). A pure Maxwellian distribution can lead to noticeable deficiencies when calculating 
the red line emissions for characteristic energies greater than about $1 \mathrm{keV}$ (Meier et al., 1989). However, mainly soft precipitating particles are expected in the cusp, hence LET are ignored.

We have taken into account that the effective lifetime of the $630.0 \mathrm{~nm}$ emission lines may vary. The metastable $\mathrm{O}\left({ }^{1} \mathrm{D}\right)$ state has a radiative lifetime of $107 \mathrm{~s}$, while the effective lifetime of the $O\left({ }^{1} \mathrm{D}\right)$ state is a function of altitude. The emission height for $630.0 \mathrm{~nm}$ varies between 180 and $400 \mathrm{~km}$, the peak emission altitude being a function of the characteristic energy in the electron beam. Our estimates of the characteristic energy indicates that the average peak emission is at $250 \mathrm{~km}$, in accordance with modelling result from Semeter et al. (2001) and Solomon et al. (1988). We are aware that the variation of the $630.0 \mathrm{~nm}$ line should be used with care. Due to the long lifetime of the $\mathrm{O}\left({ }^{1} \mathrm{D}\right)$ atom, $630.0 \mathrm{~nm}$ emission acts as a "fossil aurora" (Smith and Minow, 2006). That is $\mathrm{O}\left({ }^{1} \mathrm{D}\right)$ excited in narrow intense arcs can spread with winds and diffusion before the emission occurs. This will lead to errors in our estimates of the precipitation characteristics; in narrow structures the transport away of $\mathrm{O}\left({ }^{1} \mathrm{D}\right)$ will give a decrease in the $630.0 \mathrm{~nm}$ intensity and also the 630.0/427.8 ratio, which then leads to an overestimate of $E_{0}$. In adjacent regions, the effect will be the opposite.

The $\mathrm{N}_{2}^{+} 427.8 \mathrm{~nm}$ intensity is nearly proportional to the total incident electron energy flux (Hecht et al., 1985). Previous statistical and modelling studies have given a conversion factor from the $427.8 \mathrm{~nm}$ intensity to the total electron energy flux, varying between $210-270 \mathrm{R} /\left(\mathrm{mW} \mathrm{m}^{-2}\right)$ (Deehr and Egeland, 1972; Rees et al.,1976; Kasting and Hays, 1977; Strickland et al., 1989). In this study we have used a conversion factor of $233 \mathrm{R} /\left(\mathrm{mW} \mathrm{m}^{-2}\right.$ ) (Strickland et al., 1989).

In principle the intensity ratios $844.6 / 427.8,630.0 / 427.8$ and 557.7/427.8, can all be used to estimate the characteristic energy of the primary precipitating electrons. To this end we have studied 3 slightly different approaches: Hecht et al. (1999) and references therein, Vallance-Jones et al. (1987) and Rees et al. (1988) and references therein. The first model uses the ratios 844.6/427.8 and 630.0/427.8, and from this model it is also possible to deduce a scaling factor of oxygen $\left(f_{O}\right)$, which represent changes in the $\mathrm{O} / \mathrm{N}_{2}$ ratio at altitudes between 110-140 km (Christensen et al., 1997). The second use the ratio 557.7/427.8 and the third model use $630.0 / 427.8$, neither account for variations of the neutral atmospheric composition. Since $630.0 \mathrm{~nm}$ requires knowledge of $\mathrm{O}$ relative to $\mathrm{N}_{2}$ in order to deduce $E_{0}$ accurately, the neutral atmospheric composition should be included (Strickland et al., 1989). This is more relevant during night time. All models have used the MSIS (Mass Spectrometer Incoherent Scatter) model atmosphere for neutral densities. Typically, during increased geomagnetic activity, the scaling factor of oxygen will decrease, while the one for $\mathrm{O}_{2}$ increase. It is also a trend that the characteristic energy will decrease when $f_{O}$ decrease (Hecht et al., 1989). In general, it is known that the $\mathrm{O} / \mathrm{N}_{2}$ ratio decreases with increasing latitude, particularly during disturbed conditions. This could influence the brightness ratio, because it is directly proportional to the $\mathrm{O}$ scaling above $130 \mathrm{~km}$. This is especially true for polar nights in the absence of $\mathrm{UV}$ radiation which creates $\mathrm{O}$ by photo dissociation of $\mathrm{O}_{2}$ during daylight conditions (Strickland et al., 1997).

In the perspective above, the reason to include the $844.6 / 427.8$ ratio in addition to the $630.0 / 427.8$, is to correct for the variation in oxygen concentration (Hecht et al., 1999). Additionally, the 844.6/427.8 has the advantage of not being affected by temporal changes in the auroral emission, as well as being almost proportional to the $\mathrm{N}_{2}^{+}$rotational temperature (Vallance-Jones et al., 1987). The emission of $557.7 \mathrm{~nm}$ is complex and it is not well understood theoretically. It appears that the 557.7/427.8 ratio is only useful for energies well above about $8 \mathrm{keV}$ (Vallance-Jones et al., 1987). Accordingly, we have only looked at the remaining ratios. It should be noted that the intensity ratios are affected by variations in the atmospheric composition as well as by scattering in the atmosphere. As much as $20 \%$ variation in the spectral intensity ratio could be expected (Gattinger et al., 1991). This would affect the level of our estimated parameters; however, the variations in the parameters will still be the same.

To estimate the characteristic energy from the optical data we used the method developed by Strickland et al. (1989) as well as the by Rees and Roble (1986). The first method is used in further modelling by Hecht et al. (1999) while the latter is used as the input for Rees et al. (1988). In our case they agree reasonable well. Both methods make use of the intensity of the $630.0 \mathrm{~nm}$ red line $\left(I_{6300}\right)$. Using this intensity to estimate the characteristics of the electron precipitation require that the spatial intensity gradients are small enough to ignore transport effects, and that $\mathrm{O}\left({ }^{1} \mathrm{D}\right)$ is at steady state. That is, variations in the precipitation have to be slower than $\sim 2$ times the altitude averaged $\mathrm{O}\left({ }^{1} \mathrm{D}\right)$ lifetime, $\tau$, which is about $30 \mathrm{~s}$ (Gustavsson et al., 2001) for a typical daytime aurora. However, assuming that the characteristic energy of the electron precipitation varies slowly, $\tau$ will be approximately constant. Then we can simplify the $\mathrm{O}\left({ }^{1} \mathrm{D}\right)$ continuity equation by integrating in altitude and obtain:

$$
\frac{d I_{6300}}{d t}=\frac{-I_{6300}}{\tau}+q
$$

where $q$ is the column excitation rate. For a constant source we get the steady state solution of $I_{S S}=\tau \cdot q$. When the column $\mathrm{O}\left({ }^{1} \mathrm{D}\right)$ excitation rate varies slowly, the observed $I_{6300}$ will not be at steady state. However, solving Eq. (3) for $\tau \cdot q$, gives a corrected estimate of the corresponding steady state intensity:

$I_{Q S S}(t)=\tau \cdot q(t) \approx I_{6300}(t)+\frac{\tau \cdot \Delta I_{6300}(t)}{\Delta t}$

This way we can improve the estimates of $E_{0}$, and we can extend the use to cases where temporal variations are not faster 


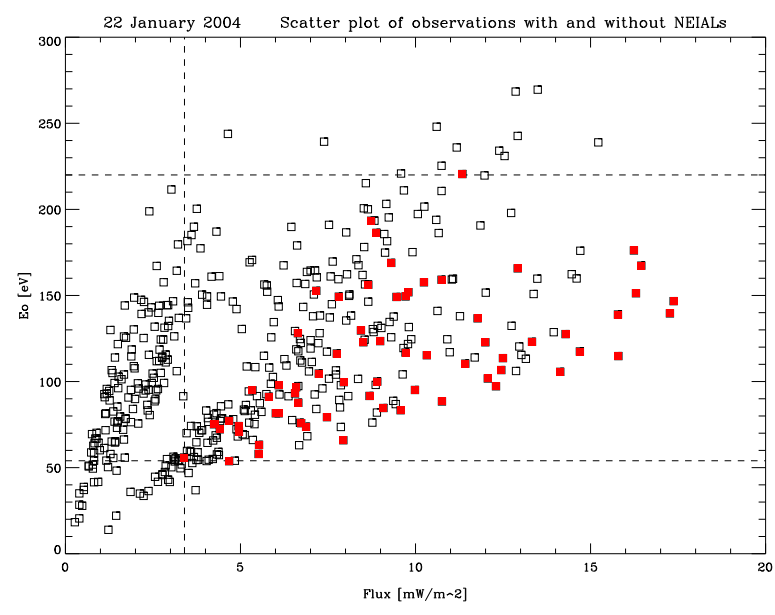

Fig. 5. The energy flux versus the characteristic energy. The red squares represent NEIALs events. Two populations can be seen. They mostly coincide with the time before and after 09:00 UT.

than about $\tau / 2$. As can be seen in the keograms in Fig. 4, the spatial structures are not sharp enough to make transport effects impact the estimates.

Energetic particle precipitating and Joule heating due to dissipation of electric currents will heat the lower thermosphere during aurora and drive vertical and horizontal transport of the atmospheric gases (Fuller-Rowell, 1985). In general, heating and $\mathrm{O} / \mathrm{N}_{2}$ ratio are anti-correlated; the ratio $\mathrm{O} / \mathrm{N}_{2}$ in the lower thermosphere (E-region) is at a minimum during maximum particle and Joule heating (Hecht et al., 1995; Christensen et al., 1997). Thus, both heating and atmospheric composition will influence the optical brightness ratio. A typical criterion of Joule heating is enhancements in both the electron density and ion temperature in the Eregion, while the electron temperature is unaffected. The Joule heating is found by using the deviation of the horizontal component of the magnetic field from the quiet level. The least active day that month, 8 January, was used for this purpose. The height-integrated Joule heating rate, $Q_{J}$, is related to the magnetic field perturbations, $\Delta H$, at ground level by; $Q_{J}=k(\Delta H)^{2}$, where $k$ is a constant (Cole, 1971). The choice of the scaling factor, which differs between the morning and evening sectors (Brekke and Rino, 1978), is taken from Duboin and Kamide (1984). We have adapted $k$ equal to $0.8 \mathrm{E}-7\left[\mathrm{Wm}^{-2}(\mathrm{nT})^{-2}\right]$, which represents an average value in the midnight-morning sector.

\section{Discussion}

The observation of Collis et al. (1991) established a clear connection between high intensity of the red line and the occurrence of NEIALs. As shown in Fig. 4, our data confirm this relationship. Our intensities ranges from 4 to $43 \mathrm{kR}$ while NEIAL are observed only at levels roughly above $15 \mathrm{kR}$. This agrees fairly well with Collis et al. (1991), who observed NEIAL at intensities between 10 and $40 \mathrm{kR}$. For comparison, typical dayside cusp emission rates for the $630.0 \mathrm{~nm}$ line at moderately disturbed conditions $\left(K_{p} \sim 2\right)$ is between 3 and $8 \mathrm{kR}$ (Zhang and Shepard, 2006). The high intensity in the red line emission is a sign of abundant low energy electron precipitation. Such precipitation is thus an important clue to the understanding of NEIALs. In Collis et al. (1991), all the NEIAL events coincided with active and high intensitiy red auroral forms in the optical data, but they do not say anything about whether they also have such strong intense red lines without NEIAL or not. In our data, however, we do have periods of red line emission above the lower limit without observing any NEIAL.

The routine EISCAT analysis of the ISR data (Fig. 3) reveals enhanced electron temperature and $T_{e}$ to $T_{i}$ ratio during the period of NEIALs. This is consistent with previous investigations, e.g. Foster et al. (1988); Rietveld et al. (1991); Wahlund et al. (1993); Forme et al. (1995). Details of the temperature variation with time are hard to obtain due to low signal to noise ratio and the fact that the analysis breaks down during the NEIAL events. However, the enhanced temperatures and electron densities during the NEIAL period is no doubt a result of particle precipitation, directly by soft particles depositing their energy in the F-layer, or indirectly by harder particles producing hot secondary electrons in the E-layer drifting upwards into the F-layer (Mæhlum et al., 1984).

Our result shows that a certain minimum intensity in all channels is required before NEIALs appear, not only the red line (Fig. 4). A closer look on other parameters such as energy flux and characteristic energy could thus be significant. In Fig. 5, the electron energy flux is plotted versus the characteristic energy. We observed that the NEIALs appear only when the flux exceeds a lower limit. The lower limit is equal to $\sim 3.4 \mathrm{~mW} / \mathrm{m}^{2}$ and the flux during NEIAL events is found to be well above this lower limit most of the time. The characteristic energy during NEIAL events was about $115 \mathrm{eV}$ on average. In contrast to the energy flux, there seems to be a lower as well as an upper limit for the characteristic energy, since NEIALs were observed only in the range from $50 \mathrm{eV}$ to $220 \mathrm{eV}$. However, considering the obviously large uncertainties in $E_{0}$, especially at values below $100 \mathrm{eV}$, these upper and lower limits should be regarded as rough estimates only.

As pointed out in Sect. 3, the observations' geomagnetic latitude and time of day are compatible with the cusp/cleft. The characteristic energies estimated above, indicate that the precipitating particles are magnetosheath particles with enhanced energy. Together with a red to green line intensity ratio much larger than 2 , increased electron densities, and large particle fluxes, we take this to indicate cusp precipitation. However, in addition to the ordinary soft cusp precipitation, there are indications of a component of higher energy:

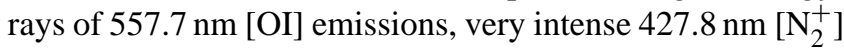
emissions, and a high energy tail seen in the DMSP satellite 
data just before the first NEIAL are observed. This augmented cusp activity is presumably due to the before mentioned CME in the solar corona prior to our observations. The presence of high energy particles in the cusp is supported by a number of recent satellite programs. In fact, it appears that the cusp is a major source of energetic charged particles for the magnetosphere (Fritz and Fung, 2005).

The auroral displays during the NEIAL period exhibited diffuse as well as discrete forms, all four lines observed with the MSP showed considerable intensities. Electron precipitation all over the energy range of auroral particles, $10 \mathrm{eV}-$ $10 \mathrm{keV}$, is thus presumably present for the period. In Fig. 6 , the red/green ratio against the energy flux for each integration periode is plotted. The period with NEIALs are marked in red. The NEIALs seem to be limited to values of the red/green ratio between 5 and 15 . The lower limit is undisputable. There is a relatively large number of points below ratio 5 and above the lower limit of $3.4 \mathrm{~mW} / \mathrm{m}^{2}$ in flux, none of which contains NEIALs. The upper limit is much less significant. There are a number of points without NEIALs above ratio 15 , but when we exclude the points with energy flux less than $3.4 \mathrm{~mW} / \mathrm{m}^{2}$, only a handful is left. Considering that after all, only a minority of the points with flux higher than $3.4 \mathrm{~mW} / \mathrm{m}^{2}$ and ratio higher than 15 contain NEIALs, this handful may well be a coincidence.

In the majority of our NEIAL events, both shoulders are detectable, albeit with different enhancement. The right shoulder, which represents ion acoustic waves travelling towards the radar, is associated with thermal- and suprathermal electrons as well as ions, while the left shoulder, which represents ion acoustic waves travelling away from the radar, is associated with soft electrons, current and ion-outflow (Rietveld et al., 1996). Furhermore, the right and left shoulder is dominating at different altitudes, typically below and above $250 \mathrm{~km}$ in altitude, respectively. The optical lines represent energy deposition of the particle precipitation at different altitudes. From comparing the ESR and MSP data, it is clear that the red line is associated with the left shoulder, while the more energetic lines are significant to the right one.

Much attention has been paid to the soft part of the particle precipitation during NEIAL. However, acknowledging the fact that the mechanisms behind NEIAL are far from well understood, the harder part of the precipitation should not be ignored. In our data we have three indicators of hard precipitation: i) increased electron density in the E-region, ii) excursions in the geomagnetic component or, equivalently, Joule heating, and iii) cosmic noise absorption. NEIALs are quite often accompanied by indication of hard particles by one or more of theses indicators, although there is not a complete correspondence. In pronounced cases, indicator i) and iii) typically occur at the same time, while the indicator ii) comes slightly ahead of them. Weaker events exhibit a more varied and less clear picture.

Energetic particles precipitation results in increased electron density at lower altitudes. This can be seen as enhanced

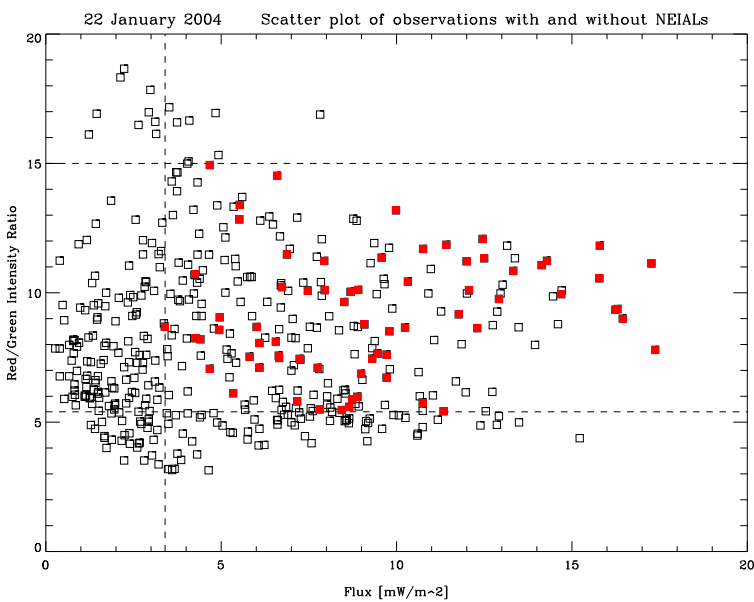

Fig. 6. The energy flux versus the intensity ratio of 630.0/557.7. The red filled squares represent NEIALs events.

backscatter power from the E-region. The backscatter is close to proportional to the electron density, and under the night time conditions of our observations, electron precipitation is the only significant source of ionisation. To a first approximation the electron density is then proportional to the square root of the electron flux (Brekke et al. 1989). In our data, energetic particle events occur simultaneous to some of the NEIAL events, for instance: 08:53, 09:10, 09:26, 09:38, 09:48, and 09:55-09:55 UT, see Fig. 1. In fact, roughly $40 \%$ of all NEIAL events are associated with hard precipitation in addition to a sufficient soft component

Energetic particles ionising the E-region will increase the electric conductivity. Provided an electric field is present, electric currents arise and a disturbance of the magnetic field is observed on ground. Our magnetometer records do show a disturbed magnetic field in period of NEIAL events, thus confirming the conclusion drawn from the radar data. The horizontal component of the field reaches a maximum excursion of $380 \mathrm{nT} 10 \mathrm{~min}$ before the commencement of the NEIAL period. This is somewhat different from the result of Buchert et al. (1999) who found a coincidence between maximum magnetic disturbance and the NEIAL occurrence.

In the auroral and polar cap regions, the cosmic radio noise absorption in the ionosphere as observed by the riometer, is mainly caused by precipitation of auroral particles from the magnetosphere. However, increased electron collision frequency due to enhanced electron temperature associated with plasma instabilities generated by large ionospheric electric fields, may also contribute to the absorption (Stauning, 1996). In our case we assume the absorption observed is the ordinary one caused by increased ionisation in the D-and E-regions by energetic particles since such particles are indicated also by the radar and magnetometer observations. During the period of NEIALs the absorption reached its maximum of $0.8 \mathrm{~dB}$ at the same time as the magnetometer 
excursion. According to Akasofu (1968) this indicates particles with characteristic energies of the order of several tens of $\mathrm{keV}$.

As pointed out by Mæhlum et al. (1984) the F-region is far from unaffected by hard precipitation. Direct interaction between the F-region plasma and the fast particles may perturb the electron velocity distribution, or the effect may be indirect by secondary electrons originating from the Eregion. The Joule heating caused by the electric currents in the E-region may represent another indirect source of disturbance of the F-region assuming that the perturbation of the E-layer propagates upwards. In our case the joule heating was $1.7 \mathrm{~mW} / \mathrm{m}^{2}$ on average for the period of interest and $10 \mathrm{~mW} / \mathrm{m}^{2}$ at maximum. Thus excursion of in magnetic field, Joule heating and other indication of E-region activity may signal the possibility of NEIAL being present.

\section{Conclusion}

By means of the Svalbard IS-radar we have observed an unusually large number of NEIAL-events over a period of one hour, very likely in the cusp region. Simultaneous auroral activity was recorded with a four channel scanning photometer, and a magnetometer and imaging riometer yielded supplementary data.

At all photometer wavelengths the intensity increased considerably at the onset of the NEIAL period and then dropped to a lower level again, immediately after the last NEIAL. Riometer absorption events and excursions of the magnetometer's horizontal component also characterised the NEIAL period. Clearly the NEIALs were accompanied by not only soft (energies less than $500 \mathrm{eV}$ ) electron precipitation which is associated with the down-shifted shoulder in the incoherent scatter spectrum, but also more energetic particles.

From the analysis for the optical observations we conclude that four conditions must be fulfilled for the NEIAL to appear:

1. The intensity of the red line as well as the other lines must be above a certain minimum

2. The characteristic energy must exceed $50 \mathrm{eV}$

3. The particle energy flux must be above $3.4 \mathrm{~mW} / \mathrm{m}^{2}$

4. The 630.0/557.7 intensity ratio must be higher than 5

When all these conditions were fulfilled, NEIALs occured in $90 \%$ of the integration periods. Only a few cases where these requirements were satisfied did not correspond to any NEIAL event.

Our observational results do neither verify nor falsify any of the theories for explaining NEIAL. The observed enhancements in both shoulders in the incoherent scatter spectrum support all three theories, provided that there exist two or more fine structures within the radar beam to account for the use of the current instability theory. The fact that soft particle precipitation clearly is present supports the parametric decay of Langmuir waves. Furthermore, since the enhancements predominantly occur in the upper part of the F-region, the ion-ion two-stream instability can not be excluded before a thorough study of the flow of $\mathrm{H}^{+}$ions during NEIAL events is done. Finally, it should be kept in mind that the three theories are not mutually exclusive.

Do the hard precipitation (energies $>500 \mathrm{eV}$ ) play any role in the production of NEIAL? The question has been touched upon in the literature (Forme et al., 1995; Forme and Fontain, 1999; Nöel et al., 2000), but so far not adequately since all these investigations are dealing nightside condition and not cusp/cleft. During our NEIAL events, hard precipitation no doubt is present, as clearly indicated by the increased electron density in the E-layer, magnetic activity and riometer absorption. A direct association between hard particles and NEIALs seems to be manifest in the enhancement of the upshifted shoulder during such precipitation. This association has not previously been addressed, and the role of hard precipitation in the generation of NEIALs may therefore deserve a closer investigation.

Acknowledgements. The authors acknowledge the University of Alaska, Fairbanks, for providing the MSP data, the Troms $\varnothing$ Geophysical Observatory (Norway) for distributing the magnetometer data and we like to thank M. Nishino for use of the riometer data. We are indebted to the director and staff of EISCAT for operating the facility and supplying the data. EISCAT is an International Association supported by China (CRIRP), Finland (SA), Germany (DFG), Japan (NIPR \& STEL), Norway (NFR), Sweden (VR) and the United Kingdom (PPARC). We are grateful to T. L. Hansen at the Troms $\varnothing$ Geophysical Observatory for useful discussions and comments.

Topical Editor M. Pinnock thanks two anonymous referees for their help in evaluating this paper.

\section{References}

Akasofu, S. I.: Polar and Magnetospheric Substorms, D. Reidel Publishing Company, Dordrecht-Holland, 1968.

Blixt, E. M., Grydeland, T., Ivchenko, N., Hagfors, T., La Hoz, C., Lanchester, B. S., Løvhaug, U. P., and Trondsen, T. S.: Dynamic rayed aurora and enhanced ion-acoustic radar echoes, Ann. Geophys., 23, 3-11, 2005, http://www.ann-geophys.net/23/3/2005/.

Brekke, A. and Rino, C. L.: High-resolution altitude profiles of the auroral zone energy dissipation due to ionospheric currents, J. Geophys. Res., 83, 2517-2524, 1978.

Brekke, A., Hall, C., and Hansen, T. L.: Auroral ionospheric conductances during disturbed conditions, Ann. Geophys., 7, 269280, 1989, http://www.ann-geophys.net/7/269/1989/.

Buchert, S. C., van Eyken, A. P., Ogawa, T., and Watanabe, S.: Naturally enhanced ion-acoustic lines seen with the EISCAT Svalbard Radar, Adv. Space Res., 23, 1699-1704, 1999. 
Christensen, A. B., Hecht, J. H., Walterscheid, R. L., Larsen, M. F., and Sharp, W. E.: Depletion of oxygen in aurora: Evidence for a local mechanism, J. Geophys. Res., 102, 22 273-22 277, 1997.

Cole, K. D.: Electrodynamic heating and movement of the thermosphere, Planet. Space Sci., 19, 59-75, 1971.

Collis, P. N., Häggström, I., Kaila, K., and Rietveld, M. T.: EISCAT radar observations of enhanced incoherent scatter spectra; their relation to red aurora and field-aligned currents, Geophys. Res. Lett., 18, 1031-1034, 1991.

Deehr, C. S. and Egeland, A.: Auroral morphology, Ann. Geophys., 28, 415-425, 1972,

http://www.ann-geophys.net/28/415/1972/

Duboin, M.-L. and Kamide, Y.: Latitudinal variations of Joule heating due to the auroral electrojets, J. Geophys. Res., 89, 245-251, 1984.

Eather, R. H. and Mende, S. B.: Systematics in Auroral Energy Spectra, J. Geophys. Res., 77, 660-673, 1972.

Fazakerley, A. N., Harra, L. K., Culhane, J. L., van Driel-Gesztelyi, L., Lucek, E., Matthews, S. A., Owen, C. J., Mazelle, C., Balogh, A., and Rème, H.: Relating near-Earth observations of an interplanetary coronal mass ejection to the conditions at its site of origin in the solar corona, Geophys. Res. Lett., 32, L13105, doi:10.1029/2005GL022842, 2005.

Forme, F. R. E.: A new interpretation on the origin of enhanced ion acoustic fluctuations in the upper ionosphere, Geophys. Res. Lett., 20, 2347-2350, 1993.

Forme, F. R. E., Fontaine, D., and Wahlund, J. E.: Two different types of enhanced ion acoustic fluctuations observed in the upper ionosphere, J. Geophys. Res., 100, 14 625-14 636, 1995.

Forme, F. R. E.: Parametric decay of beam-driven Langmuir wave and enhanced ion-acoustic fluctuations in the ionosphere: a weak turbulence approach, Ann. Geophys., 17, 1172-1181, 1999, http://www.ann-geophys.net/17/1172/1999/.

Forme, F. R. E. and Fontaine, D.: Enhanced ion acoustic fluctuations and ion outflows, Ann. Geophys., 17, 182-189, 1999, http://www.ann-geophys.net/17/182/1999/.

Foster, J. C., del Pozo, C., Groves, K., and St. Maurice, J.-P.: Radar observations of the onset of current driven instabilities in the topside ionosphere, Geophys. Res. Lett., 15, 160-163, 1988.

Frank, L. A.: Plasma in the earth's polar magnetosphere, J. Geophys. Res., 76, 5202-5219, 1971.

Frank, L. A. and Ackerson, K. L.: Observations of charged particle precipitation into the auroral zone, J. Geophys. Res., 76, 36123643, 1971.

Fritz, T. A. and Fung, S. F.: The Magnetospheric Cusp: Structure and Dynamics, Berlin Springer, Germany, 2005.

Fuller-Rowell, T. J.: A two-dimensional, high-resolution, nestedgrid model of the thermosphere, 2, Response of the thermosphere to narrow and broad electrodynamic features, J. Geophys. Res., 90, 6567-6586, 1985.

Gattinger, R. L., Vallance-Jones, A., Hecht, J. H., Strickland, D. J., and Kelly, J.: Comparison of Ground-Based Optical Observations of $\mathrm{N}_{2}$ Second Positive to $\mathrm{N}_{2}^{+}$First Negative Emission Ratios With Electron Precipitation Energies Inferred From the Sondre Stromfjord Radar, J. Geophys. Res., 96, 11341-11351, 1991.

Grydeland, T., La Hoz, C., Hagfors, T., Blixt, E. M., Saito, S., Strømme, A., and Brekke, A.: Interferometric observations of filamentary structures associated with plasma instabil- ity in the auroral ionosphere, Geophys. Res. Lett., 30, 1338, doi:10.1029/2002GL016362, 2003.

Grydeland, T., Blixt, E. M., Løvhaug, U. P., Hagfors, T., La Hoz, C., and Trondsen, T. S.: Interferometric radar observations of filamented structures due to plasma instabilities and their relation to dynamic auroral rays, Ann. Geophys., 22, 1115-1132, 2004, http://www.ann-geophys.net/22/1115/2004/.

Gustavsson, B., Sergienko, T., Rietveld, M. T., Honary, F., Steen, Å., Brändström, B. U. E., Leyser, T. B., Aruliah, A. L., Aso, T., Ejiri, M., and Marple, S.: First tomographic estimate of volume distribution of HF-pump enhanced airglow emission, J. Geophys. Res., 106, 29 105-29 124, 2001.

Hecht, J. H, Christensen, A. B., and Pranke, J. B.: High-Resolution Auroral Observations of the OI(7774) and OI(8446) Multiplets, Geophys. Res. Lett., 12, 605-608, 1985.

Hecht, J. H., Christensen, A. B., Strickland, D. J., and Meier, R. R.: Deducing Composition and Incident Electron Spectra From Ground-Based Auroral Optical Measurements: Variations in Oxygen Density, J. Geophys. Res., 94, 13 553-13 563, 1989.

Hecht, J. H., Christensen, A. B., Gutierrez, D. J., Kayser, D. C., Sharp, W. E., Sharber, J. R., Winningham, J. D., Frahm, R. A., Strickland, D. J., and McEwen, D. J.: Observations of the neutral atmosphere between 100 and $200 \mathrm{~km}$ using ARIA rocket-borne and grond-based instruments, J. Geophys. Res., 100, 17285 $17298,1995$.

Hecht, J. H., Christensen, A. B., Strickland, D. J., Majeed, T., Gattinger, R. L., and Vallance Jones, A.: A comparison between auroral particle characteristics and atmospheric composition inferred from analyzing optical emission measurements alone and in combination with incoherent scatter radar measurements, J. Geophys. Res., 104, 33-44, 1999.

Heikkila, W. J. and Winningham, D. J.: Penetration of magnetosheath plasma to low altitudes through the dayside magnetic cusps, J. Geophys. Res., 76, 883-891, 1971.

Kasting, J. F. and Hays, P. B.: A comparison between $\mathrm{N}_{2}^{+} 4278-\AA$ emission and electron flux in the auroral zone, J. Geophys. Res., 82, 3319-3323, 1977.

Lyons, L. R.: Formation of auroal arcs via magnetosphericionosphere coupling, Rev. Geophys., 30, 93-111, 1992.

Meier, R. R., Strickland, D. J., Hecht, J. H., and Christensen, A. B.: Deducing Composition and Incident Electron Spectra From Ground-Based Auroral Optical Measurements: A Study of Auroral Red Line Processes, J. Geophys. Res., 94, 13 541-13 552, 1989.

Mæhlum, B. N., Hansen, T., Brekke, A., Holt, O., and Folkestad, K.: Preliminary results from a study of the F-region heating during an intense aurora observed by EISCAT, J. Atmos. Terr. Phys., 46, 619-623, 1984.

Neubert, T. and Christiansen, F.: Small-scale, field-aligned currents at the top-side ionosphere, Geophys. Res. Lett., 30, 2010, doi:10.1029/2003GL017808, 2003.

Newell, P. T. and Meng, C.-I.: Mapping the dayside ionosphere to the magnetosphere according to particle precipitation characteristics, Geophys. Res. Lett., 19, 609-612, 1992.

Newell, P. T., Ruohoniemi, J. M., and Meng, C.-I.: Maps of precipitation by source region, binned by IMF, with internal convection streamlines, J. Geophys. Res., 109, A10206, doi:10.1029/2004JA010499, 2004.

Nöel, J.-M. A., St.-Maurice, J.-P., and Blelly, P.-L.: Nonlinear 
model of short-scale electrodynamics in the auroral ionosphere, Ann. Geophys., 18, 1128-1144, 2000,

http://www.ann-geophys.net/18/1128/2000/.

Ogawa, Y., Buchert, S. C., Fujii, R., Nozawa, S., and Forme, F.: Naturally enhanced ion- acoustic lines at high altitudes, Ann. Geophys., 24, 3351-3364, 2006, http://www.ann-geophys.net/24/3351/2006/.

Ogilvie, K. W.: Auroral electron energy spectra, J. Geophys. Res., 73, 2325-2332, 1968.

Rees, M. H. and Maeda, K.: Auroral Electron Spectra, J. Geophys. Res., 78, 8391-8394, 1973.

Rees, M. H. and Luckey, D.: Auroral Electron Energy Derived From Ratio of Spectroscopic Emissions 1. Model Computations, J. Geophys. Res., 79, 5181-5186, 1974.

Rees, M. H., Romick, G. J., Anderson, H. R., and Casserly Jr., R. T.: Calculation of Auroral Emissions From Measured Electron Precipitation: Comparison With Observation, J. Geophys. Res. 81, 5091-5096, 1976.

Rees, M. H. and Roble, R. G.: Excitation of $\mathrm{O}\left({ }^{1} \mathrm{D}\right)$ atoms in aurorae and emission of the [OI] 6300- $\AA$ line, Can. J. Phys, 64, 16081613, 1986.

Rees, M. H., Lummerzheim, D., Roble, R. G., Winningham, J. D., Craven, J. D., and Frank, L. A.: Auroral Energy Deposition Rate, Characteristic Electron Energy, And Ionospheric Parameters Derived from Dynamics Explorer 1 Images, J. Geophys. Res., 93, 12 841-12 860, 1988.

Rietveld, M. T., Collis, P. N., and St.-Maurice, J.-P.: Naturally Enhanced Ion Acoustic Waves in the Auroral Ionosphere Observed With the EISCAT 933-MHz Radar, J. Geophys. Res., 96, 1929119305, 1991.

Rietveld, M. T., Collis, P. N., van Eyken, A. P., and Løvhaug, U. P.: Coherent echoes during EISCAT UHF Common Programmes, J. Atmos. Terr. Phys., 58, 161-174, 1996.

Romick, G. J.: The detection and study of the visible spectrum of aurora and airglow, in: Methods for Atmospheric Radiometry, edited by: McNutt, D. P., p. 63, Int. Soc. for Opt. Eng., Bellingham Wash., 1976.

Sato, M., Yamagishi, H., Kato, Y., and Nishino, M.: Quicklook system of auroral absorption images by imaging riometer, Antarctic Records, 36(2), 251-267, 1992.

Sedgemore-Schulthess, K. J. F., Lockwood, M., Trondsen, T. S., Lanchester, B. S., Rees, M. H., Lorentzen, D. A., and Moen, J.: Coherent EISCAT Svalbard Radar spectra from the dayside cusp/cleft and their implication for transient field-aligned currents, J. Geophys. Res., 104, 24 613-24 624, 1999.

Sedgemore-Schulthess, F. and St.-Maurice, J.-P.: Naturally enhanced ion-acoustic spectra and their interpretation, Surv. Geophys., 22, 55-92, 2001.

Semeter, J., Lummerzheim, D., and Haerendel, G.: Simultaneous Multispectral Imaging of the Discrete Aurora, J. Atmos. Sol-Terr. Phys., 63, 1981-1992, 2001.

Smith, R. and Minow, J.: Misleading aspects of the use of the oxygen red line for optical studies of the cusp and cleft aurora, http://www.gi.alaska.edu/space/roger_smith/papers/alfven/ alfven.htm, 2006.
Solomon, S. C., Hays, P. B., and Abreu, V. J.: The Auroral 6300 Å Emission: Observations and Modeling, J. Geophys. Res., 93, 9867-9882, 1988.

Stauning, P.: Investigations of ionospheric radio wave absorption processes using imaging riometer techniques, J. Atmos. Terr. Phys. 58, 753-764, 1996.

Strickland, D. J., Meier, R. R., Hecht, J. H., and Christensen, A. B.: Deducing Composition and Incident Electron Spectra From Ground-Based Auroral Optical Measurements: Theory and Model Results, J. Geophys. Res., 94, 13 527-13 539, 1989.

Strickland, D. J., Daniell Jr., R. E., Jasperse, J. R., and Basu, B.: Transport-Theoretic Model for the Electron-Proton-Hydrogen Atom Aurora, 2. Model Results, J. Geophys. Res., 98, 21 533$21548,1993$.

Strickland, D. J., Majeed, T., Christensen, A. B., Hecht, J. H.: Remote sensing of atomic oxygen in auroral rocket experiments using topside zenith viewing $\mathrm{O} / \mathrm{N}_{2}$ brightness ratios, J. Geophys. Res., 102, 2475-2482, 1997.

Strømme, A., Belyey, V., Grydeland, T., La Hoz, C., Løvhaug, U. P., and Isham, B.: Evidence of naturally occurring wave-wave interactions in the polar ionosphere and its relation to naturally enhanced ion acoustic lines, Geophys. Res. Lett., 32, L05103 doi:10.1029/2004GL020239, 2005.

Vallance Jones, A., Gattinger, R. L., Shih, P., Meriwether, J. W., Wickwar, V. B., and Kelly, J.: Optical and Radar Characterization of a Short-Lived Auroral Event at High Latitude, J. Geophys. Res. 92, 4575-4589, 1987.

Wahlund, J. E., Opgenoorth, H. J., Häggström, I., Winser, K. J., and Jones, G. O. L.: EISCAT Observations of the Topside Ionospheric Ion Outflows During Auroral Activity: Revisited, J. Geophys. Res., 97, 3019-3037, 1992a.

Wahlund, J.-E., Forme, F. R. E., Opgenoorth, H. J., Persson, M. A. L., Mishin, E. V., and Volokitin, A. S.: Scattering of electromagnetic waves from a plasma: enhanced ion acoustic fluctuations due to ion-ion two-stream instabilities, Geophys. Res. Lett., 19, 1919-1922, 1992b.

Wahlund, J.-E., Opgenoorth, H. J., Forme, F. R. E., Persson, M. A. L., Häggström, I., and Lilensten, J.: Electron energization in the topside auroral ionosphere: on the importance of ion-acoustic turbulence, J. Atmos. Terr. Phys., 55, 623-645, 1993.

Wannberg, G., Wolf. I., Vanhainen, L.-G., Koskenniemi, K., Röttger, J., Postila, M., Markkanen, J., Jacobsen, R., Stenberg, A., Larsen, R., Eliassen, S., Heck, S., and Huuskonen, A.: The EISCAT svalbard radar: a case study in modern incoherent scatter radar system design, Radio Sci., 32, 2283-2307, 1997.

Yamagishi, H., Nishino, M., Sato, M., Kato, Y., Kojima, M., Sato, N., and Kikuchi, T.: Development of imaging riometers, Antarctic Records, 36(2), 227-250, 1992.

Zhang, S. P. and Sheperd, G. G.: The daytime cusp aurora in the $\mathrm{O}\left({ }^{1} \mathrm{D}\right)$ emission observed by WINDII on UARS, http://stpl.cress. yorku.ca/ $\sim$ sheng/cusp_final.pdf, 2006. 